\title{
Biochar from vegetable wastes: agro-environmental characterization
}

\author{
Snigdhendubala Pradhan ${ }^{1}$ - Ali H. Abdelaal ${ }^{1} \cdot$ Kamal Mroue $^{2}$ - Tareq Al-Ansari ${ }^{1} \cdot$ Hamish R. Mackey $^{1}$ (D) \\ Gordon McKay ${ }^{1}$
}

Received: 28 May 2020 / Accepted: 21 September 2020 / Published online: 30 October 2020

(c) The Author(s) 2020

\begin{abstract}
Considering the global issue of vegetable wastes generation and its impact on the environment and resources, this study evaluated the conversion of four largely produced vegetable wastes (cauliflower, cabbage, banana peels and corn cob residues) into biochar. Each waste was tested individually and as a combined blend to assess feedstock influences on biochar properties. In addition, various pyrolysis temperatures ranging from $300^{\circ} \mathrm{C}$ to $600{ }^{\circ} \mathrm{C}$ and two particle size fractions (less than $75 \mu \mathrm{m}$, $75-125 \mu \mathrm{m}$ ) were considered. Biochars were characterized for various properties that can influence the biochars' effectiveness as a soil amendment. It was found that pyrolysis temperature was the most dominant factor on biochar properties, but that individual feedstocks produced biochars with different characteristics. The biochars had characteristics that varied as follows: $\mathrm{pH}$ 7.2-11.6, ECE $0.15-1.00 \mathrm{mS} \mathrm{cm}{ }^{-1}$, CEC $17-\mathrm{cmol}_{\mathrm{c}} \mathrm{kg}^{-1}$ and $\zeta$-potential -0.24 to $-43 \mathrm{mV}$. Based on optimal values of these parameters from the literature, cauliflower and banana peels were determined to be the best feedstocks, though mixed vegetable waste also produced good characteristics. The optimum temperature for pyrolysis was around $400{ }^{\circ} \mathrm{C}$, but differed slightly $\left(300-500{ }^{\circ} \mathrm{C}\right)$ depending on the distinct feedstock. However, smaller particle size of biochar application was always optimal. Biochar yields were in the range of $20-30 \%$ at this temperature range, except for corn cobs which were higher. This study demonstrates that pyrolysis of dried vegetable wastes is a suitable waste valorization approach to produce biochar with good agricultural properties.
\end{abstract}

Keywords Food waste $\cdot$ Kitchen waste $\cdot$ Pyrolysis $\cdot$ Biochar properties $\cdot$ Soil amendment $\cdot$ Particle size

\section{Introduction and background}

Food production is paramount to human well-being, and the global demand for food productivity is expected to grow by 59-98\% by 2050 (FAO 2017). Degradation of soil fertility and nutrient depletion are common threats to agroecosystems and a challenge for modern agricultural practices for balancing soil fertility factors. Global food production is further threatened through water security because of increasing

Electronic supplementary material The online version of this article (https://doi.org/10.1007/s42773-020-00069-9) contains supplementary material, which is available to authorized users.

Hamish R. Mackey

hmackey@hbku.edu.qa

1 Division of Sustainable Development, College of Science and Engineering, Hamad Bin Khalifa University, Doha, Qatar

2 Qatar Environment and Energy Research Institute, Doha, Qatar population and climate change, requiring improved agricultural water efficiency (Gao et al. 2020). Biochar, a carbonrich material produced by pyrolysis of biomass material, is a suitable soil amendment to provide long-lasting carbon enrichment of the soil while enhancing water retention (Safian et al. 2020); macro- and micro-nutrient retention and microbial activity of the soil (Pokharel et al. 2020), which can also aid in nitrogen fixation. Biochar achieves these benefits due to its highly porous structure, wide range of functional groups (Lam et al. 2020; Foong et al. 2020), high negative surface charges and large cation exchange capacity (CEC) (Bradford and Hsiao 1982).

Biomasses from agricultural wastes are highly suitable for pyrolysis and biochar production due to their high lignocellulosic content. Pyrolysis is an effective process that offers agronomic and environmental benefits by reducing waste biomass volumes by 44-90\% (Sait et al. 2012; Sakhiya et al. 2020). The pyrolysis temperature and the specific feedstock employed are the primary factors influencing biochar yields and characteristics. Characteristics of biochar that 
distinguish its effectiveness as an amendment to improve soil fertility, water retention capacity and crop productivity include $\mathrm{pH}$, cation exchange capacity (CEC), organic carbon content (OC) and nutrients adsorption capacity (Jien and Wang 2013; Junna et al. 2016; Alotaibi and Schoenau 2019).

Jien and Wang (2013) reported biochar of $\mathrm{pH} 9.94$ and CEC $22.3 \mathrm{cmol}_{\mathrm{c}} \mathrm{kg}^{-1}$ produced from wood at $700{ }^{\circ} \mathrm{C}$ increases the $\mathrm{pH}$ in Paleudults soil from 3.95 to 4.65, CEC from 7.41 to $9.26 \mathrm{cmol} \mathrm{kg}^{-1}$ and saturated hydraulic conductivity from 16.7 to $30.0 \mathrm{~cm} \mathrm{~h}^{-1}$ after amendment at $2.5 \%$. Palm tree residue biochar produced at a lower temperature of $300{ }^{\circ} \mathrm{C}$ with $\mathrm{pH}$ of 7.67, ECE of $1.22 \mathrm{mS} \mathrm{cm}^{-1}$ and CEC of $9.86 \times 10^{-2}$ meq showed a $3.5 \%$ increase in water holding capacity than biochar produced at $600{ }^{\circ} \mathrm{C}$ when added at $50 \mathrm{t} \mathrm{ha}^{-1}$ to sand (Alotaibi and Schoenau 2019). For fruit bunch biochar, optimum water retention in sandy soil was observed for biochar produced at $400{ }^{\circ} \mathrm{C}$. These aspects indicate that biochar properties and performance are highly dependent on feedstock types, pyrolysis temperatures and soil types. In addition to improving water retention capacity, biochar produced at lower temperature is effective to improve soil fertility and plant growth. For instance, biochar produced from three different types of agricultural wastes at $300{ }^{\circ} \mathrm{C}$ with $\mathrm{pH}$ of $6.93-8.01$, ECE of $0.404-3.975 \mathrm{mS} \mathrm{cm}^{-1}$ and CEC of $18.8-50.5 \mathrm{cmol}_{\mathrm{c}} \mathrm{kg}^{-1}$ improved the yield of Suaeda salsa from $11.7 \%$ to $115 \%$ in saline soil (Junna et al. 2016).

In 2017, it was estimated that 1.3 billion tonnes of food waste is generated per year globally within the food supply chain, in which approximately $0.31 \mathrm{~kg}$ of food waste is generated per person daily (FAO 2017). Around 630 million metric tonnes (MMT) of fruit and vegetables are wasted during agricultural production, transportation and packaging, postharvest handling, distribution/retail activities and by consumers. Of fruit and vegetable waste, $35 \%$ are banana peels (220 MMT), $8 \%$ are cabbage waste (50 MMT), 2\% are cauliflower and brassicas (13 MMT), 15\% are potato peels (94 MMT) and 20\% are tomatoes (126 MMT) (Gustavsson et al. 2011; Sagar et al. 2018). Such fractions can easily be collected from supermarkets and from kitchen preparation side waste of canteens and restaurants (Abdelaal et al. 2019). It is therefore useful to find potential outlets for these waste fractions. According to the European Union, approximately 143 billion EUR can be recovered by recycling the 88 MMT of food wastes per year generated in the region (Stenmarck et al. 2016). While composting and anaerobic digestion are obvious choices (Al-Rumaihi et al. 2020), biogas is not always a competitive energy source and biochar provides a stable, non-odorous soil amendment with lower transportation costs than composting.

Pyrolysis studies have assessed various types of biomass feedstock for biochar such as industrial byproducts, animal wastes, sewage sludge and forest byproducts (Elkhalifa et al.
2019; Saleem et al. 2019; Reza et al. 2020). However, pyrolysis of vegetable wastes, particularly the largest fractions mentioned above, has received less attention. Cheng et al. (2018) undertook pyrolysis of purple cabbage with $\mathrm{ZnCl}_{2}$ activation and acid-leaching processes to create a nitrogendoped carbon-based electrocatalyst for oxygen reduction. The electrocatalyst promoted high oxygen reduction activity due to high contents of pyridinic- and pyrrolic-nitrogen inside the prepared carbon material. However, very few other studies exist. In particular, there is a lack of assessment of pyrolysis conditions on vegetable wastes and how that influences characteristics that may benefit agricultural applications, or how the blend of such wastes, as may be expected in post-consumer collection from plate or food preparation waste impacts characteristics. Such wastes are very different in composition to the non-edible agricultural residues typically used for pyrolysis and therefore are expected to produce different characteristics to many other biochars. This may be in part due to the high moisture content that makes direct pyrolysis uneconomical. However, in arid areas, solar drying can be easily implemented. In such cases, appropriate size reduction prior to drying can be highly effective to enhance surface area. However, excessive size reduction can be highly energy intensive, particularly with wet biomass. Therefore, providing one suitable size reduction step that supports both solar drying and pyrolysis is of benefit.

Thus, a set of objectives was defined to check the possibility of biochar production from common vegetable and consumer fruit wastes: raw banana peels, cabbage wastes and cauliflower wastes. In addition to this, we also selected to investigate corncobs, since they are significantly different in composition and also can be commonly collected from plate waste. Conversion of these four vegetables wastes and their mixture to biochar under various temperatures was undertaken to understand how food waste composition and pyrolysis temperature influence biochar properties. In addition, as feedstock particle size could influence feedstock drying and pyrolysis, two particle sizes were also assessed. This study focuses on a detailed analysis of the biochar properties of relevance to soil including particle size, CEC, surface structure, adsorption of nutrients and fraction of organics which will effect microbial activity, water retention and plant growth.

\section{Materials and methods}

\subsection{Feedstock preparation}

To prepare biochar, cauliflower and cabbage wastes were collected from a waste bin in the preparation section of a university canteen in Qatar. A detailed process of biochar production is demonstrated in Fig. 1. Corn and raw banana 


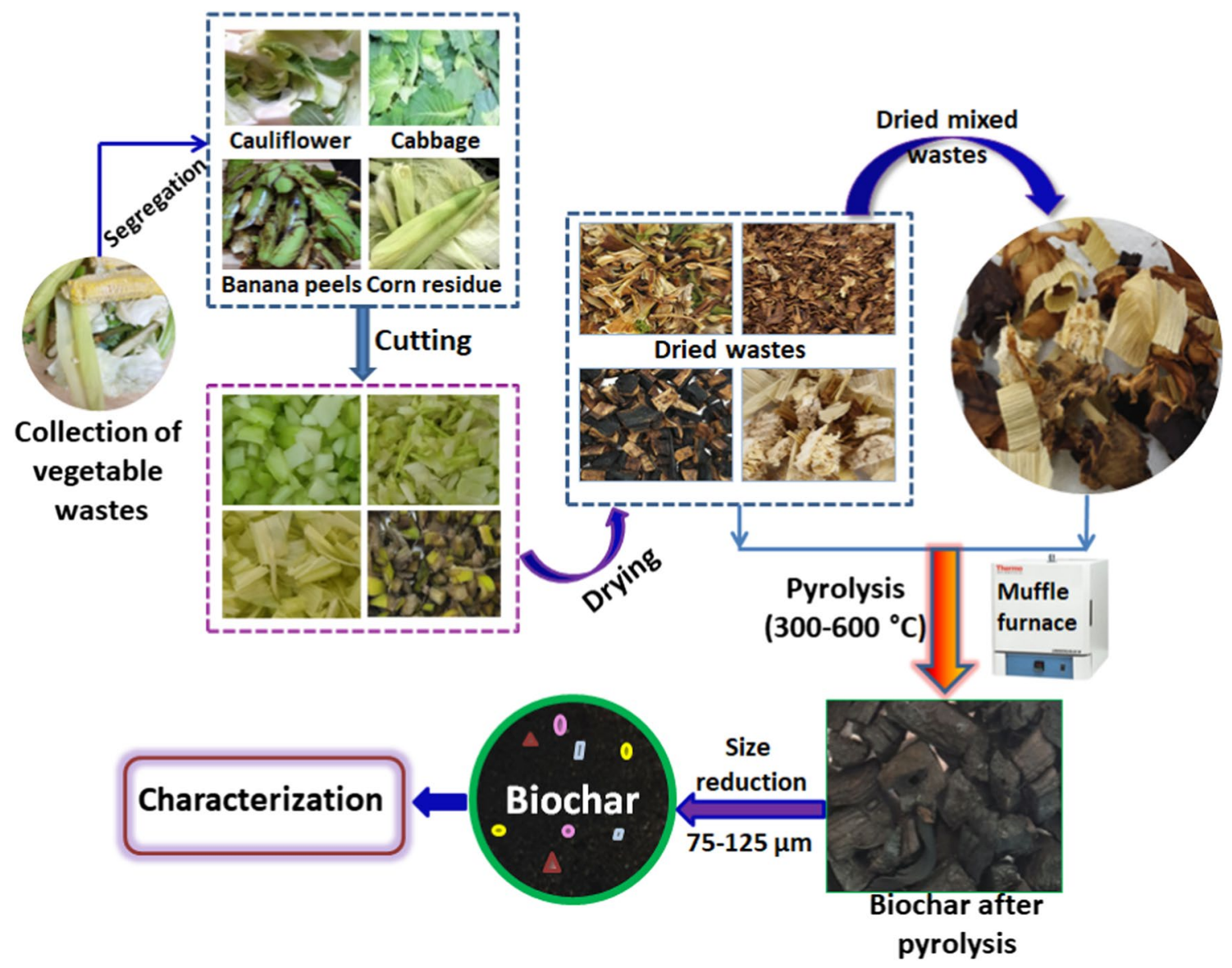

Fig. 1 A detailed process of biochar production from vegetable wastes

were collected from a local supermarket. After collection, the leaves and cobs of corn, and banana peels were separated from the edible portion to use as a feedstock. After collection, the wastes were washed thoroughly with tap water several times to remove impurities. Vegetable wastes were then segregated into different batches and cut into small pieces $(<3 \mathrm{~cm})$. The weight of all batches was measured before and after drying at $75^{\circ} \mathrm{C}$ in a Fisher Scientific Isotemp mechanical convection laboratory oven until completely dry (Mazac 2016).

\subsection{Biochar production}

Five feedstocks were prepared for pyrolysis under different conditions. These were each of the four individual dried food wastes and an equal-weighted mixture of the four wastes. Pyrolysis was conducted in the absence of oxygen using a muffle furnace (Lindberg Blue M-3504, Thermo Scientific) in batch mode at the following temperatures to assess their influence on biochar yield and properties: $300,400,500$ and $600{ }^{\circ} \mathrm{C}$ (Xue et al. 2019). Fifty grams of each dried feedstock was pyrolyzed at the four different temperature conditions to produce biochar. Samples were put in a furnace and raised to the defined temperature at a ramp rate of $5{ }^{\circ} \mathrm{C} \min ^{-1}$ and held at the desired temperature for $15 \mathrm{~min}$. After pyrolysis, the samples were left inside the furnace to cool down and then weighed to determine the yield by the equation below:

Yield of biochar $(\%)=\frac{\text { Weight of biochar }(\mathrm{g})}{\text { Weight of oven }- \text { dried wastes }(\mathrm{g})} \times 100$.

\subsection{Grain size analysis}

After the yield determination, samples were ground manually by a stainless steel spice grinder for one to two minutes. A sieve shaker with sieves ranging from $75 \mu \mathrm{m}$ to $710 \mu \mathrm{m}$ was then used to classify the particle size of the resulting biochar (ASTM 2007). After sieve analysis, two particle sizes, those passing through $75 \mu \mathrm{m}$ and $125 \mu \mathrm{m}$, were considered to characterize the properties of biochar and to check 
the effective size to apply with soil as an amendment for plant growth.

\subsection{Elemental analysis of biochar}

A combustion-type elemental analyzer (EA 3000, Eurovector) was used to determine carbon (C), nitrogen $(\mathrm{N})$ and hydrogen $(\mathrm{H})$ content for the two different particle sizes of biochar. Measurement was taken at a furnace temperature of $980{ }^{\circ} \mathrm{C}$, with a carrier flow of $121 \mathrm{~mL} \mathrm{~min}{ }^{-1}$. Before analysis, biochar samples were oven-dried. Samples ranging from 0.50 to $1.5 \mathrm{mg}$ were weighed and acetanilide was used as a reference standard.

\subsection{Proximate analysis of biochar}

Proximate analysis was conducted to measure volatile matter, fixed carbon and ash content of biochar followed by the American Society for Testing and Materials (ASTM) D7582-15 method (ASTM 2013). The thermal analysis of the biochars was performed by using an SDT-2960 simultaneous DSC-TGA thermal analyzer (TA instruments). The temperature followed a linear heating ramp at a rate of $5{ }^{\circ} \mathrm{C} \mathrm{min}{ }^{-1}$ from $40{ }^{\circ} \mathrm{C}$ to $105{ }^{\circ} \mathrm{C}$ to remove the moisture. The temperature was held at $105^{\circ} \mathrm{C}$ for $7 \mathrm{~min}$ and then again increased at $30^{\circ} \mathrm{C} \mathrm{min}-1$ from $105^{\circ} \mathrm{C}$ to $850{ }^{\circ} \mathrm{C}$ with a gas flow rate of $\mathrm{N}_{2}$ and $\mathrm{O}_{2} 99 \mathrm{~mL} \mathrm{~min}^{-1}$.

Fixed carbon content was calculated by the following equation:

Fixed carbon $(\%)=100 \%-\operatorname{Ash}(\%)+$ Volatile matter $(\%)$.

After measurement of $\mathrm{CHN}$ and ash content, the percentage of oxygen content $(\mathrm{O})$ was determined by the following equation (Zhao et al. 2017):

$\mathrm{O} \%=100 \%-(\mathrm{C} \%+\mathrm{H} \%+\mathrm{N} \%+\mathrm{Ash} \%)$.

\subsection{Analysis of surface area and morphology of biochar}

The Brunauer-Emmett-Teller (BET) surface area of biochar samples was determined by $\mathrm{N}_{2}$ gas sorption analysis at $77 \mathrm{~K}$ between a relative pressure of $0.05-0.35$ by using an ASAP 2020 plus surface area analyzer (Micrometrics). The surface morphology of biochar samples was analyzed with a scanning electron microscope (SEM) (Quanta 650FEG, FEI) following gold sputter coating. Images were taken under high voltage at an acceleration voltage of $5.00 \mathrm{kV}$.

\subsection{FT-IR analysis}

Fourier transform infrared ray (FT-IR) measurement was taken using 64 scans per sample by a Thermo Scientific Nicolet iS50 FT-IR spectrometer at a resolution of $4 \mathrm{~cm}^{-1}$. The samples were crushed with $\mathrm{KBr}$ in a mortar at a ratio of $1: 100$, and the pressed pellets were immediately analyzed in the region of $400-4000 \mathrm{~cm}^{-1}$ (Huang et al. 2020).

\subsection{XPS analysis}

The X-ray photoelectron spectroscopy (XPS) measurements were taken by a Thermo-Fisher ESCALAB 250Xi instrument using a monochromatic $\mathrm{Ag} \mathrm{K} \alpha$ anode $\mathrm{X}$-ray beam of $1486.6 \mathrm{eV}$ as the XPS excitation source for acquiring all photoelectron spectra. The curve fitting procedure was performed on the Thermo Advantage software. A $180^{\circ}$ hemisphere electron analyzer was used with an overall energy resolution better than $0.5 \mathrm{eV}$. The samples were placed with a beam incident angle of $45^{\circ}$ to the surface normal and a normal emission for data acquisition. All the energy positions were calibrated with respect to the $\mathrm{C}-\mathrm{C}$ components in the $\mathrm{C} 1 \mathrm{~s}$ spectra locating at $284.8 \mathrm{eV}$. Data deconvolution was conducted with a GL30\% profile after a Shirley background subtraction.

\subsection{Chemical properties of biochar}

Various chemical properties of the biochar such as $\mathrm{pH}$, electrical conductivity (ECE), zeta $(\zeta)$ potential, cation exchange capacity (CEC) and phosphorous adsorption (P) were determined by following different standard procedures. The $\mathrm{pH}$ and electrical conductivity of biochar were measured by using a calibrated $\mathrm{pH}$ meter and conductivity meter (Orion Star A121 and A329, Thermo Scientific, respectively).

Media and water were mixed at a ratio of 1:5 in a shaker for $1 \mathrm{~h}$ at $150 \mathrm{rpm}$ before measuring $\mathrm{pH}$ and ECE (Dai et al. 2013). Surface charge properties given by the $\zeta$-potential were measured on Zetasizer Nano-ZS (Malvern) (Zhao et al. 2017; Liu et al. 2020). $\zeta$-potential was determined in aqueous suspension $(0.02 \%, \mathrm{w} / \mathrm{v})$ at $\mathrm{pH}$ values ranging from 3 to 14 .

Mineral content of the food waste feedstock and biochar samples were measured by inductively coupled plasma optical emission spectroscopy (ICP-OES) using an Agilent 5110 ICP-OES that enables synchronous radial and axial measurement. Before analysis, $500 \mathrm{mg}$ of sample was digested with $8 \mathrm{~mL}$ nitric acid and $3 \mathrm{~mL}$ hydrogen peroxide with a microwave digestion system (Ethos UP, Milestone). Then, $10 \mathrm{~mL}$ $\mathrm{HCl}$ was added to the digested samples for complete reflux. After digestion samples were diluted with deionized water.

The cation exchange capacity (CEC) of biochar was determined by using ammonium exchange $\left(\mathrm{NH}_{4}{ }^{+}\right)$, following 
ASTM D7503-10 (2010). The concentration of ammonia was measured by segmented flow analyzer (Sans+, Skalar). Phosphorus adsorption is a major property of biochar and a nutrient for plant growth. Phosphorus adsorption was measured by preparing a synthetic solution of $\mathrm{KH}_{2} \mathrm{PO}_{4}$ in deionized water. Initially, biochar samples were washed by deionized water and oven-dried at $80{ }^{\circ} \mathrm{C}$ to remove any initial phosphate adsorbed on biochar surface (Lou et al. 2016). The stock solution of $\mathrm{P}$ was prepared using $\mathrm{KH}_{2} \mathrm{PO}_{4}$ which contained $4.558 \mathrm{mg} \mathrm{L}^{-1}$ of P. Adsorption of $\mathrm{P}$ was assessed using $50 \mathrm{mg}$ of biochar as the adsorbent in $25 \mathrm{~mL}$ stock solution of $\mathrm{KH}_{2} \mathrm{PO}_{4}$ without adjustment of the $\mathrm{pH}$. Samples were kept for $24 \mathrm{~h}$ to allow equilibrium adsorption capacity of phosphorous by biochar. After $24 \mathrm{~h}$, the samples were filtered with $0.45 \mu \mathrm{m}$ polyvinylidene fluoride membrane filters (Durapore, Merck Millipore Ltd) and the final concentration of $\mathrm{P}$ was estimated using a segmented flow analyzer $\left(\mathrm{San}^{++}\right.$, Skalar, The Netherland). The adsorption capacity of the biochar for $\mathrm{P}$ was calculated as per the equation given below:

$\frac{\mathrm{mg} \text { of P uptake }}{\mathrm{g} \text { of biochar }}=\frac{V}{m} \times\left(C_{0}-C_{f}\right)$,

where $V=$ volume of $\mathrm{KH}_{2} \mathrm{PO}_{4}$ solution (L); $m=$ mass of biochar $(\mathrm{g}) ; C_{0}=$ initial concentration of $\mathrm{P}\left(\mathrm{mg} \mathrm{L}^{-1}\right) ; C_{f}=$ final concentration of $\mathrm{P}\left(\mathrm{mg} \mathrm{L}^{-1}\right)$.

\subsection{Statistical analysis}

Statistical analysis of the factors temperature, feedstock and particle size was conducted using a 3-way independent ANOVA in the JASP statistical package. Where significant differences were observed $(\alpha=0.05)$, Tukey's post hoc test was utilized for multiple comparisons if Levene's test was not significant, or Games-Howell post hoc test if Levene's test indicated inequality of variance (indicated in text with "G-H"). As Games-Howell is not provided for pairwise interaction comparisons, Tukey's $p$ value is reported in these instances regardless of the outcome from Levene's test. Effect size was measured using the $\omega^{2}$ statistic for ANOVA.

\section{Results and discussion}

\subsection{Biochar yield}

The yield of biochar from the five different batches of feedstocks and four different pyrolysis temperatures of $300-600{ }^{\circ} \mathrm{C}$ is shown in Fig. 2. Higher biochar recovery was observed at lower pyrolysis temperatures for all feedstock batches. As the lowest temperature tested was $300{ }^{\circ} \mathrm{C}$, this demonstrates negligible condensation of aliphatic compounds and less losses of $\mathrm{CH}_{4}, \mathrm{H}_{2}$ and $\mathrm{CO}$ (Brantley et al.

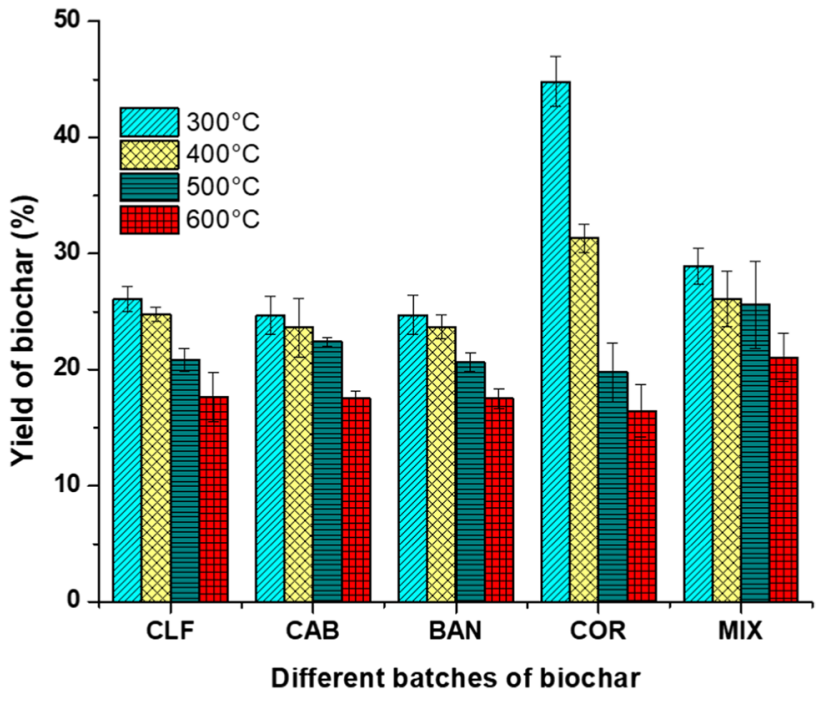

Fig. 2 Yield of biochar from different batches of feedstocks produced at different pyrolysis temperatures. $C L F$ cauliflower wastes, $C A B$ cabbage wastes, $B A N$ banana peels, $C O R$ corn wastes, $M I X$ mixture of cauliflower, cabbage, banana and corn wastes

2015). Corn biochar had the maximum yield compared to other feedstocks at $300{ }^{\circ} \mathrm{C}$ (Thangalazhy-Gopakumar et al. 2010), while the other three individual-waste feedstocks had similar yields at all temperatures. The yields of biochar for all the feedstocks were reduced with increasing pyrolysis temperature from $300{ }^{\circ} \mathrm{C}$ to $600{ }^{\circ} \mathrm{C}$ due to greater losses of volatile components at the higher pyrolysis temperatures. Yield of corn wastes biochar was most strongly influenced by increasing temperature, where its yield at $300{ }^{\circ} \mathrm{C}$ was $44.8 \%$ and it decreased rapidly between $300{ }^{\circ} \mathrm{C}$ and $500{ }^{\circ} \mathrm{C}$ down to $19.8 \%$, similar to the other wastes. The decreasing trend demonstrates the dehydration of hydroxyl groups and thermal degradation of lignocellulosic structures with increasing temperature (Thangalazhy-Gopakumar et al. 2010).

\subsection{Elemental composition and proximate analysis}

Figure 3 represents the variation of elemental composition, proximate analysis and mineral content of the five feedstocks and their biochars produced at different pyrolysis temperatures. The carbon (C) content of biochar increased with increasing pyrolysis temperature, whereas the $\mathrm{H}$ and $\mathrm{O}$ contents decreased (Fig. 3a); however, no particular trend was observed in nitrogen $(\mathrm{N})$. The highest nitrogen content was observed in biochar at $400{ }^{\circ} \mathrm{C}$ which was attributed to the incorporation of nitrogen into complex structures that were resistant to lower temperature and not easily volatilized.

There was a gradual decrease in hydrogen and oxygen at higher temperature indicated by the lower ratios of $\mathrm{O} / \mathrm{C}$ and $\mathrm{H} / \mathrm{C}$ due to structural transformations and loss of hydrophilic 

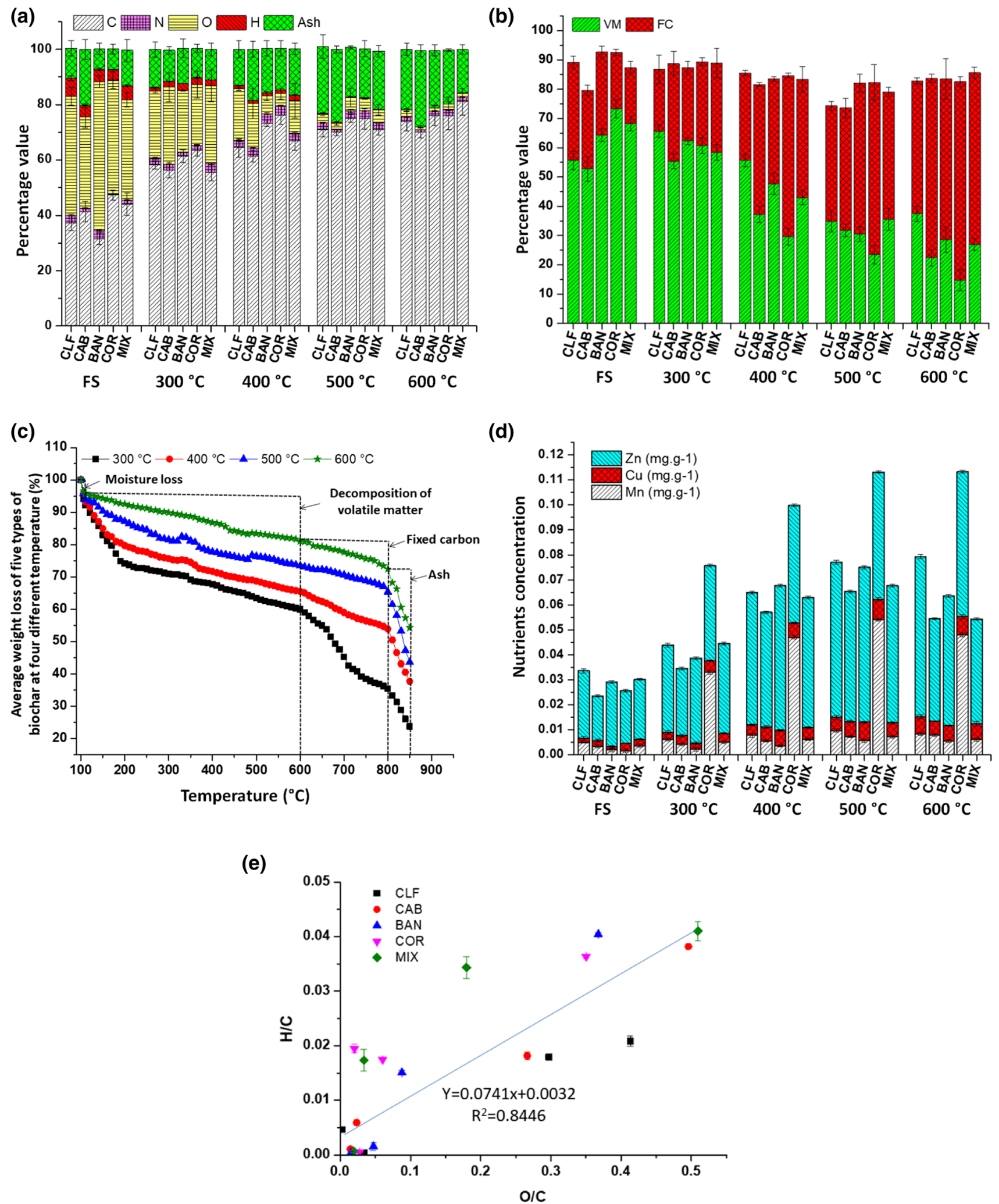

Fig. 3 a Elemental and b proximate analysis of different feedstocks and biochar produced from feedstocks, $\mathbf{c}$ average weight loss of the five feedstock biochars at each of the four pyrolysis temperatures used, $\mathbf{d}$ nutrients analysis of feedstocks and biochar at different pyrolysis temperatures and e correlation between $\mathrm{H} / \mathrm{C}$ and $\mathrm{O} / \mathrm{C}$ of biochar of different feedstocks and biochar produced at different pyrolysis temperatures. $F S$ feedstock, $C L F$ cauliflower wastes, $C A B$ cabbage wastes, $B A N$ banana peels, $C O R$ corn residue, $M I X$ mixture of cauliflower, cabbage, banana and corn wastes, $C$ carbon, $N$ nitrogen, $O$ oxygen, $H$ hydrogen, $V M$ volatile matter, $F C$ fixed carbon 
surface functional groups. A positive correlation was observed between $\mathrm{O} / \mathrm{C}$ and $\mathrm{H} / \mathrm{C}$ in Fig. 3e which indicates the degree of $\mathrm{C}$ stability. In general, lower hydrogen and oxygen contents were associated with greater hydrophobicity of the biochar by Hardy et al. (2017). O/C ratio indicates the polarity and abundance of polar oxygen-containing surface functional groups in biochar and $\mathrm{H} / \mathrm{C}$ ratio indicates the aromatic content and stability of the biochar. Pyrolysis results in condensation of carbon chains at higher temperatures and loss of $\mathrm{O}$ and $\mathrm{H}$ increases resistance to microbial degradation in the soil (Kookana et al. 2011). The $\mathrm{C}$ concentration and the $\mathrm{H} / \mathrm{C}$ and $\mathrm{O} / \mathrm{C}$ ratios control the formation of surface functional groups and have a large influence on nutrients adsorption. Biochar having a lower $\mathrm{H} / \mathrm{C}$ ratio has been correlated with promoting plant growth (Bonanomi et al. 2017).

From Fig. 3b, it was observed that as the VM decreased $\mathrm{FC}$ and ash content increased with increasing pyrolysis temperature due to the progressive concentration of minerals and volatilization of organic matter. The decrease in VM exhibits a similar trend with the biochar yield from $300{ }^{\circ} \mathrm{C}$ to $600{ }^{\circ} \mathrm{C}$ (Fig. 2), while an opposite trend was found for the content of FC. These results confirmed that the increase in temperature enhanced the stability of biochar for the loss of volatile fractions and increased FC.

A range of boundary temperatures $\left(100-850{ }^{\circ} \mathrm{C}\right)$ for separating VM, FC, and ash content are shown in the TGA profile by the average weight loss of five feedstock biochars produced at four different temperatures (Fig. 3c). All biochar samples showed a similar thermal degradation profile with the weight loss proportionally increasing with pyrolysis temperature, which according to Jindo et al. (2014) could be mostly associated with the loss of lignocellulosic fractions that did not decompose during the pyrolysis process and thermal decomposition of minerals and salts from the biochar.

The increased ash content at high temperature resulted from progressive concentration of inorganic constituents that was confirmed by mineral analysis as shown in Fig. 3d. Some minerals decreased with increasing pyrolysis temperature from $500{ }^{\circ} \mathrm{C}$ to $600{ }^{\circ} \mathrm{C}$, which might be due to volatilization as gas or liquid (Pituello et al. 2015). Thus, the content of ash decreased in some biochars at temperatures greater than $600{ }^{\circ} \mathrm{C} . \mathrm{Zn}, \mathrm{Cu}$ and $\mathrm{Mn}$ concentrations were relatively similar between the various vegetable waste biochars, with exception of $\mathrm{Mn}$, which was almost an order of magnitude higher in corn cob waste biochar. $\mathrm{Zn}$ was the highest in cauliflower and banana waste biochar, while $\mathrm{Cu}$ was generally the highest in corn cob waste, but showed some variation depending on temperature.

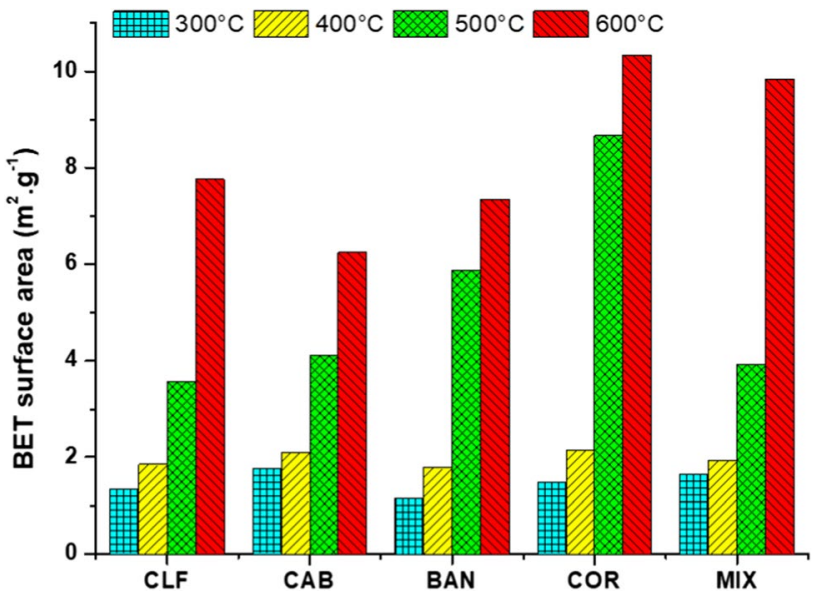

Fig. 4 BET surface area of biochar produced at different pyrolysis temperatures. $C L F$ cauliflower wastes, $C A B$ cabbage wastes, $B A N$ banana peels, $C O R$ corn residue, $M I X$ mixture of cauliflower, cabbage, banana and corn wastes

\subsection{Biochar surface area}

The BET surface area of biochar from five batches of feedstocks with different temperature conditions is shown in Fig. 4. Surface area of biochars from different feedstocks increased with increasing temperature and is exponentially correlated. BET surface area for corn waste biochar was similar to that reported by Hale et al. (2013) of $8 \mathrm{~m}^{2} \mathrm{~g}^{-1}$ at $600{ }^{\circ} \mathrm{C}$. Corn waste biochar had the highest BET surface area of the different vegetable wastes for biochars produced at $400{ }^{\circ} \mathrm{C}$ and above.

The order of surface area was dependent on pyrolysis temperature indicating the different structures of various components in the vegetable biomass and their different volatilization and carbonization with temperature. Although high surface area can increase soil water holding capacity, its effects are not as significant as CEC (Wang et al. 2019). For instance, Piash et al. (2016) proved water hyacinth biochar with low BET surface area still had a high water holding capacity of $495 \pm 11.39 \%$ as well as good nutrient retention ability.

\section{4 pH, ECE, CEC and phosphorous adsorption}

The $\mathrm{pH}$ and conductivity are two properties of biochar that strongly influence soil fertility. The effect of pyrolysis temperature on these properties for each of the different waste substrates is shown in Fig. 5 and is significant with strong effect $\left(p<0.001, \omega^{2}=0.899\right)$. The influence of feedstock was small $\left(p<0.001, \omega^{2}=0.022\right)$ and no significant differences existed using $\mathrm{G}-\mathrm{H}$ post hoc tests. The $\mathrm{pH}$ values of all the five batches of biomass were found within a range of 4.5-6.1. In contrast, the biochar $\mathrm{pH}$ from the different 
(a)

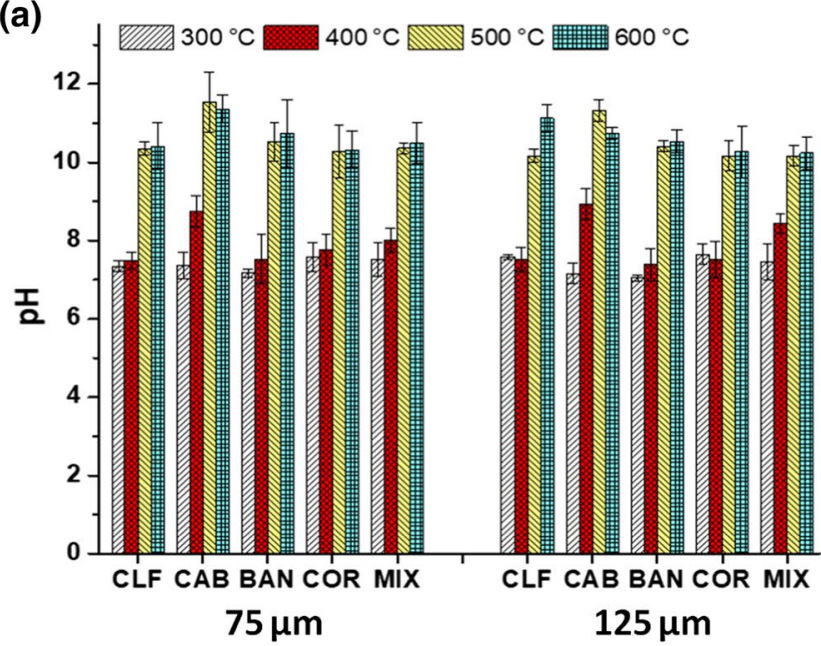

(c)

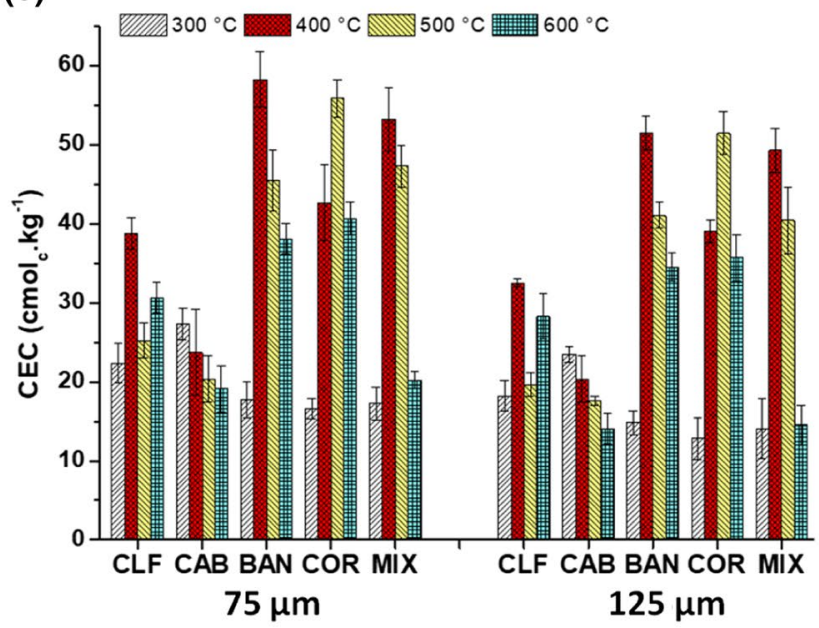

Fig. 5 Influence of a pH, b electrical conductivity (ECE), c cation exchange capacity (CEC) and $\mathbf{d}$ phosphorus (P) adsorption with particle size and pyrolysis temperature for different feedstock biochars.

batches of feedstock were more than 7 and increased with increasing pyrolysis temperature, with a distinctive increase between $400{ }^{\circ} \mathrm{C}$ and $500{ }^{\circ} \mathrm{C}$ for all samples. Values for $\mathrm{pH}$ of the individual biochars were statistically similar between $300{ }^{\circ} \mathrm{C}$ and $400{ }^{\circ} \mathrm{C}$, except for cabbage which showed an increase $(p<0.001)$. Similarly, results were similar for $\mathrm{pH}$ at temperatures of $500{ }^{\circ} \mathrm{C}$ and $600{ }^{\circ} \mathrm{C}(p=0.274, \mathrm{G}-\mathrm{H})$ (Fig. 5a). The effects of particle size of the different biochars had no influence on the $\mathrm{pH}(p=0.440)$. Significant interaction was observed between temperature and feedstock $\left(p<0.001, \omega^{2}=0.020\right)$ with differences caused by feedstock observed at temperatures of $400{ }^{\circ} \mathrm{C}$ and $500{ }^{\circ} \mathrm{C}$.

Rafiq et al. (2016) reported the $\mathrm{pH}$ of biochar from various biomass types ranges from acidic to alkaline but $\mathrm{pH}$ is commonly reported to be alkaline with increasing pyrolysis temperature. However, some studies have reported acidic biochar produced ( $\mathrm{pH}$ 4.0-5.8) from hardwood, softwood,

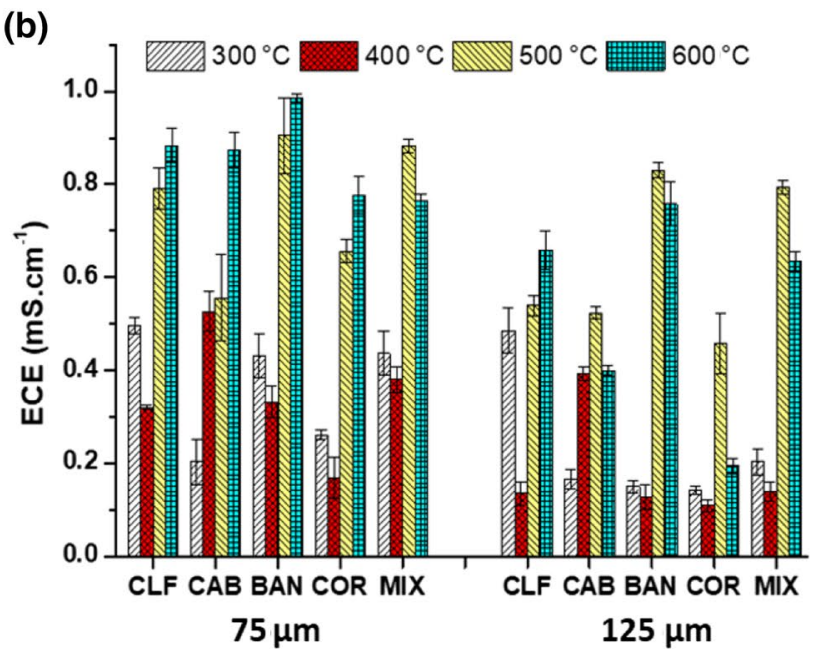

(d)

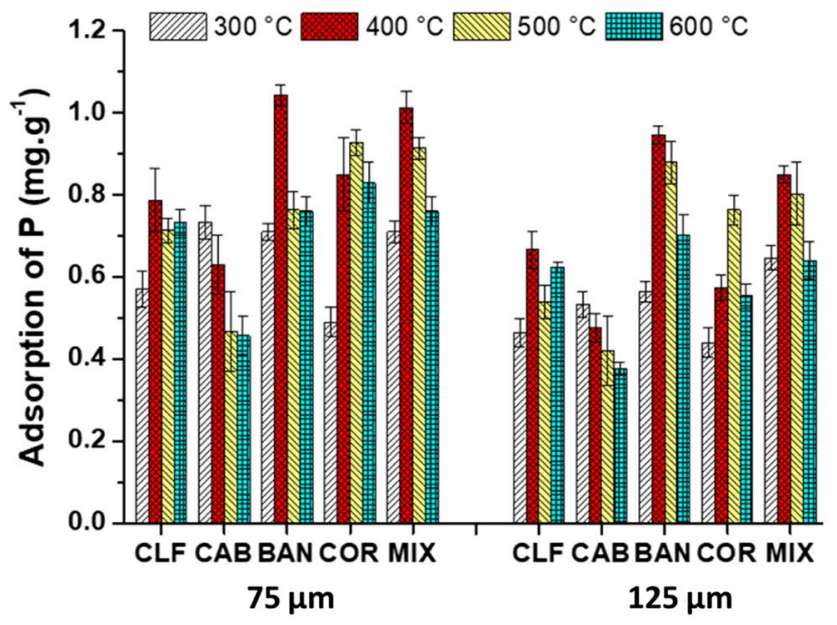

$C L F$ cauliflower wastes, $C A B$ cabbage wastes, $B A N$ banana peels, $C O R$ corn wastes, $M I X$ mixture of cauliflower, cabbage, banana and corn wastes

algae, switchgrass (Panicum virgatum) and other grasses at a temperature range from $300{ }^{\circ} \mathrm{C}$ to $600{ }^{\circ} \mathrm{C}$ (Ippolito et al. 2016). Jeffery et al. (2017) reported the $\mathrm{pH}$ between 6.5 and 7.5 is very compatible to adsorption nutrients and is effective for plant germination and growth. The authors suggested biochar with a $\mathrm{pH}$ from 7 to 9 is effective for tropical zones where soils are acidic in nature, confirming the suitability of biochars produced in this study at temperatures of $300{ }^{\circ} \mathrm{C}$ and $400{ }^{\circ} \mathrm{C}$ for plant germination and growth. In contrast to $\mathrm{pH}, \mathrm{ECE}$ values showed differences for particle size $\left(\omega^{2}=0.113\right)$, temperature $\left(\omega^{2}=0.577\right)$ and feedstock $\left(\omega^{2}=0.090\right)$, all having individual and interactive effects with a $p<0.001$ (Fig. 5b). The smaller diameter particle size $(75 \mu \mathrm{m})$ had higher ECE values than the larger particle size $(125 \mu \mathrm{m})$, possibly due to increased surface area with smaller particles. 
Temperature showed a more varied impact, with most feedstocks showing a minimum ECE at $400{ }^{\circ} \mathrm{C}$, with the exception of cabbage waste $\left(300^{\circ} \mathrm{C}\right)$ and maximum ECE at either $500{ }^{\circ} \mathrm{C}$ or $600{ }^{\circ} \mathrm{C}$. In general, a consistent ECE response with temperature between the two particle sizes was observed. Yuan et al. (2011) reported ECE values of biochar produced from sludge increases with increased $\mathrm{pH}$ and pyrolysis temperature due to the decrease in soluble ions and increased mineral formation. However, Wang et al. (2019) reported that the ECE of maize straw biochars decreased with increasing temperature and $\mathrm{pH}$, demonstrating that ECE may vary with feedstock type and temperature as seen with this studies' results. Patriquin et al. (1993) reported soil microbial activity, water holding capacity and solubility of nutrients in soil decline with increasing ECE. Therefore, the most desirable ECE is achieved at $400{ }^{\circ} \mathrm{C}$ for most feedstocks in this study.

Cation exchange capacity (CEC) is an important factor to measure soil's ability to hold and exchange nutrients such as nitrogen, calcium and potassium (Weil and Brady 2017), while its ability to bind with phosphorus, an important anionic nutrient, is also crucial. Soil with a lower cation exchange capacity is not able to retain nutrients and the nutrients are easily leached under wetting events. Therefore, application of biochar with high CEC in soil will help to improve the nutrient assimilation efficiency by the crop during the growing season and also improve the ability of the soil to adsorb and retain nutrients from other sources at non-growing times (Kizito et al. 2019). Different behavior of CEC was observed for biochar produced from different feedstocks, particle size and temperature as shown in Fig. 5c. Each factor was statistically significant $(p<0.001)$ with the effect of feedstock and temperature being large $\left(\omega^{2}=0.213\right.$ and 0.393 , respectively). The CEC was less for $125 \mu \mathrm{m}$ particle size than $75 \mu \mathrm{m}$, although relative patterns between temperature and feedstock were similar and the differences small $\left(\omega^{2}=0.025\right)$. The CEC for the biochars of cauliflower, banana peel and the mixed feedstocks was the greatest at $400{ }^{\circ} \mathrm{C}$ (Fig. 5c), while cabbage waste showed its maximum CEC at $300{ }^{\circ} \mathrm{C}$ and corn cob at $500{ }^{\circ} \mathrm{C}$. Only cabbage waste showed a consistent trend with temperature, decreasing almost linearly as the temperature increased. All others showed their minimum at either 300 or $600{ }^{\circ} \mathrm{C}$, with both temperatures typically producing a low CEC. Mukherjee et al. (2011) and Lehman et al. (2011) both reported the CEC of biochars from different feedstocks increase from $250{ }^{\circ} \mathrm{C}$ to $400{ }^{\circ} \mathrm{C}$ and then decrease with increasing pyrolysis temperatures and found a minimum at $600{ }^{\circ} \mathrm{C}$. Such behavior is expected with increasing pyrolysis temperature due to the oxidation of the carbon compounds and loss of carboxyl groups in biochar (Luo et al. 2018). There is a confirmation by Lehman et al. (2011) who reported that much of the CEC of biochars pyrolyzed at low temperatures may arise due to the presence of non-carbonized organic matter. However, Mulabagal et al. (2015) observed in their study an increase in CEC of biochar with increasing temperature for various feedstocks up to the maximum tested temperature of $600{ }^{\circ} \mathrm{C}$. Therefore, the observations of this study seem to fit well with the general literature.

The highest CEC was from banana peels (58.2 $\left.\mathrm{cmol}_{\mathrm{c}} \mathrm{kg}^{-1}\right)$, although both corn cob $\left(58.2 \mathrm{cmol}_{\mathrm{c}} \mathrm{kg}^{-1}\right)$ and mixed feedstock $\left(53.2 \mathrm{cmol}_{\mathrm{c}} \mathrm{kg}^{-1}\right)$ were statistically similar, all at $75 \mu \mathrm{m}$ particle size. At $125 \mu \mathrm{m}$ size, corn cob gave the highest CEC value. Although cabbage biochar shows the minimum CEC, its value is still greater than $20 \mathrm{cmol}_{\mathrm{c}} \mathrm{kg}^{-1}$, meaning it can be effective to hold nutrients and support plant growth (Mukherjee et al. 2011). Very similar behavior to $\mathrm{CEC}$ was observed for $\zeta$-potential, with a high degree of correlation between the two $\left(R^{2}=0.72\right.$ for $75 \mu \mathrm{m}$ biochar and $\mathrm{R}^{2}=0.69$ for $125 \mu \mathrm{m}$ biochar) as shown in Fig. S1. This is expected as a higher negative surface charge provides a stronger attraction to cations. The particle size also played an important role in the $\zeta$-potential with the smaller $75 \mu \mathrm{m}$ biochar particles showing a relatively more negative surface charge $(p<0.001)$. Therefore, grinding of the biochar can be used to develop target surface charge properties that will influence CEC.

Phosphorous (P) is a finite resource with concerns over its future supply and availability. Therefore, in addition to CEC, the ability to hold anionic phosphate is also important. Maximum phosphorus adsorption was generally a result of pyrolysis at $400-500{ }^{\circ} \mathrm{C}$, except, like CEC, for cabbage which showed maximum phosphorus adsorption when produced at $300{ }^{\circ} \mathrm{C}$ (Fig. 5d). The degree of dependence on temperature, however, was not as noticeable for phosphorus adsorption as it was for CEC. Overall, a positive correlation was observed between CEC and phosphorus adsorption by the biochar produced from different feedstocks, as shown in Fig. S2, with a pooled feedstock $\mathrm{R}^{2}$ of 0.74 for $75 \mu \mathrm{m}$ biochar and 0.67 for $125 \mu \mathrm{m}$ biochar.

\subsection{FT-IR analysis}

Biochar derived from different feedstocks shows the presence of aromatic, aliphatic and alcohol compounds with different behaviors of peak intensity at 400 and $600{ }^{\circ} \mathrm{C}$ compared with biomass (Fig. 6). The bands at about 2700 and $3400 \mathrm{~cm}^{-1}$ correspond to aliphatic $\mathrm{C}-\mathrm{H}, \mathrm{O}-\mathrm{H}$ and $\mathrm{N}-\mathrm{H}$ stretching vibration, illustrated in Table S1. These are found maximum in biomass and least in biochar produced at $600{ }^{\circ} \mathrm{C}$ (Hossain et al. 2011). The maximum peak at $3400 \mathrm{~cm}^{-1}$ in the biomass decreased with increasing temperature and less stretching was observed in the biochar produced at $600{ }^{\circ} \mathrm{C}$. This bond represents the stretching vibration of hydroxyl groups and indicates that organic $\mathrm{O}-\mathrm{H}$ groups are very unstable at increasing temperatures 

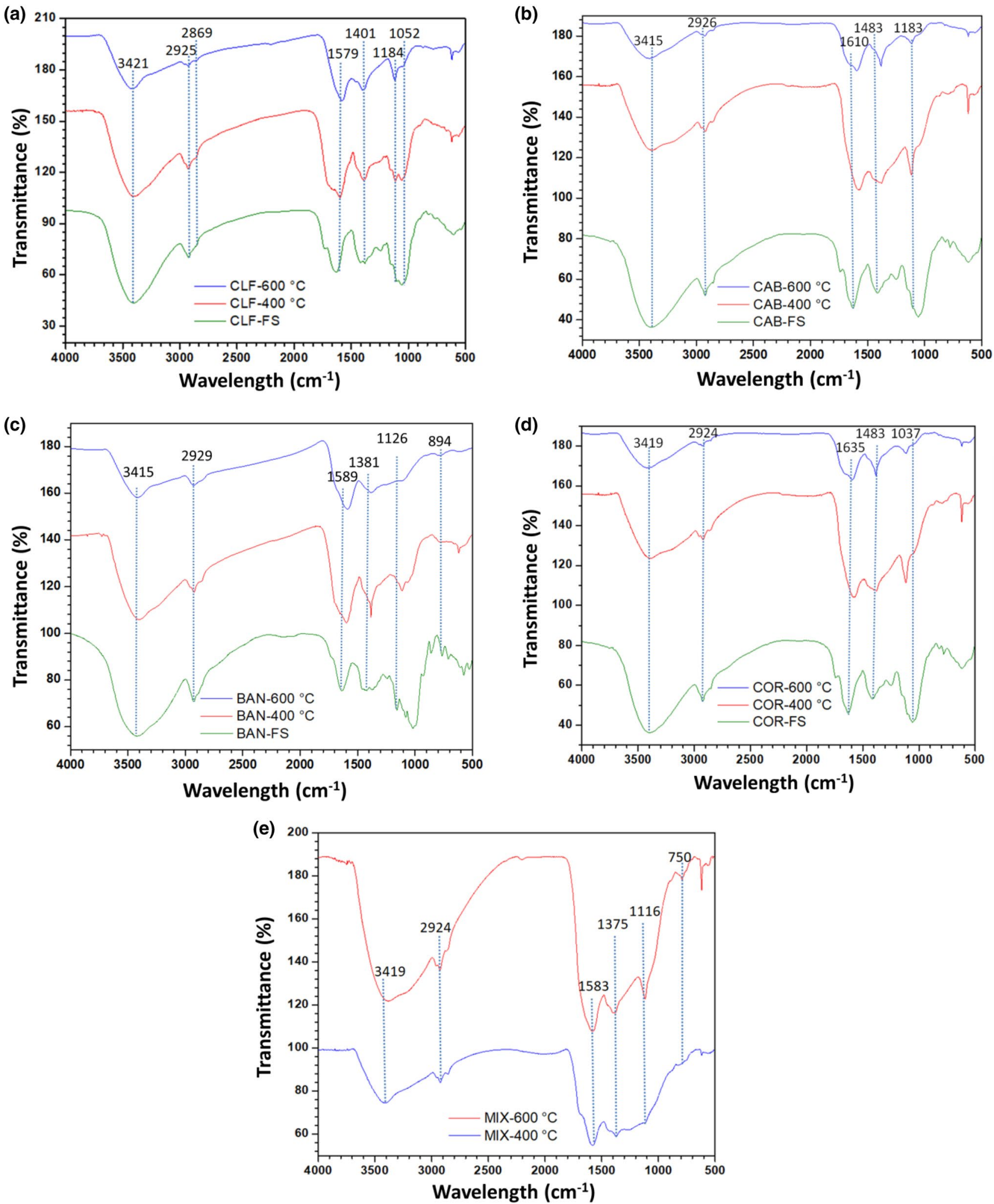

Fig. 6 The FT-IR spectrum of different feedstocks and biochars produced at $400{ }^{\circ} \mathrm{C}$ and $600{ }^{\circ} \mathrm{C}$. $F S$ feedstocks, $C L F$ cauliflower wastes, $C A B$ cabbage wastes, BAN banana peels, COR corn wastes, MIX mixture of cauliflower, cabbage, banana and corn wastes 
(Hossain et al. 2011; Chen et al. 2012). It is also attributed to acceleration in dehydration reactions of the biomass (Chen et al. 2012).

The visible bands at $1250-1420 \mathrm{~cm}^{-1}$ in biomass were assigned to $\mathrm{C}-\mathrm{O}$ stretching of aromatic ester (Chen et al. 2012) and these bonds were removed by increasing temperatures. This was supported by removal of the peak at 2924-2956 $\mathrm{cm}^{-1}$ in biomass with increasing pyrolysis temperature which is attributed to the presence of alkene (C-H) groups in carbohydrates (Chun et al. 2004). Aliphatic stretching vibration reduced as the temperature increased to $600{ }^{\circ} \mathrm{C}$, possibly due to the breaking of the weak bonds between the $\mathrm{C}$ and the $\mathrm{H}$ of the alkyl groups (Chen et al. 2012).

Similarly, the bands in the region of $1250-1800 \mathrm{~cm}^{-1}$ (alkanes and aromatics) also decrease with increase in the pyrolysis temperature, most notably in the area relating to polyphenols. The large peak at $1461-1640 \mathrm{~cm}^{-1}$ is related to $\mathrm{O}-\mathrm{H}$ together with $\mathrm{C}=\mathrm{C}$ and $\mathrm{C}=\mathrm{O}$ in the aromatic ring that indicated the presence of polyphenols, and also slightly decreased with increasing temperature (Lin et al. 2007). These peaks are due to the presence of primary, secondary and tertiary alcohols, phenols, ethers and esters showing the $\mathrm{C}-\mathrm{O}$ stretching and $\mathrm{O}-\mathrm{H}$ deformation vibrations (Chen et al. 2012). The decrease in the intensities of these bands showed that the surface concentration of the acidic functional groups has sufficiently decreased. However, there is an alteration in aromatic structure of biochar samples in comparison with biomass samples.

The stable peak at $1583 \mathrm{~cm}^{-1}$ in biochar represents the $\mathrm{C}=\mathrm{C}$ ring stretching vibration of lignin (Chen et al. 2012) and is more prevalent in biomass. The peaks between 500 and $900 \mathrm{~cm}^{-1}$ shown in Fig. 6, corresponding to an aromatic $\mathrm{C}-\mathrm{H}$ stretching vibration, indicates the presence of adjacent aromatic hydrogen in the biochar at $600{ }^{\circ} \mathrm{C}$ sample that is not seen in biomass sample. High peak intensity of the wagging vibrations of $\mathrm{C}-\mathrm{H}$ bonds of biochar at 400 and $600{ }^{\circ} \mathrm{C}$ indicated the stability of the aromatic and heteroaromatic compounds and possible cyclization. These results are in agreement with the observed changes in elemental atomic ratios which suggest an increase in the carbonization as a result of cracking and the rebuilding of aromatic rings.

FT-IR analysis indicates the maximum CEC of biochar at low temperature is due to the presence of various charged groups. Oxygen $(\mathrm{O})$ containing alcohol, carbonyl and carboxylate functional groups are generally believed to contribute to biochar cation exchange capacity (CEC) because they may carry a negative charge and serve as sorption sites for cations. Thus, the distribution of $\mathrm{O}$ and $\mathrm{N}$ containing functional groups greatly influences the relative hydrophilic/ hydrophobic nature of biochar surfaces.

\subsection{XPS analysis}

The chemical composition of feedstocks and biochar at 400 and $600{ }^{\circ} \mathrm{C}$ was evaluated by XPS shown in Fig. S3. The results of deconvolution of the $\mathrm{C} 1 \mathrm{~s}$ spectrum illustrate five bands at 284.76, 286.35, 287.75, 285.85 and $288.8 \mathrm{eV}$ which can be assigned to $\mathrm{sp}^{2}$ hybridized carbon $(\mathrm{C}-\mathrm{C})$, hydroxyl $(\mathrm{C}-\mathrm{OH})$ and carbonyl $(\mathrm{C}-\mathrm{O})$, amines $(\mathrm{C}-\mathrm{N})$ and carboxyl $(\mathrm{O}=\mathrm{C}-\mathrm{OH})$, respectively (Naderi et al. 2016). The $\mathrm{O} 1 \mathrm{~s}$ band of both feedstocks and biochar was deconvoluted into three primary peaks (Fig. $\mathrm{S} 4)$, acidic amides $(\mathrm{O}=\mathrm{C}-\mathrm{N})$ at $531.18 \mathrm{eV}$; carbonyl oxygen $(\mathrm{O}=\mathrm{C}-\mathrm{O})$ at $532.66 \mathrm{eV}$ and $\mathrm{O}-\mathrm{C}-\mathrm{O}$ at $533.26 \mathrm{eV}$. Furthermore, the N1s spectrum of biochar is deconvoluted into two Lorentzian peaks, with the binding energy of 400.00 and $399.61 \mathrm{eV}$ which can be attributed to pyrrolic $\mathrm{N}$ and pyridinic $\mathrm{N}$, respectively. The XPS data agree with the findings in FT-IR that indicates a loss of functional groups and predominance of $\mathrm{C}-\mathrm{C}$ bonding based on the $\mathrm{C} 1 \mathrm{~s}$ spectra, particularly a loss of alcohol and carboxylic acid groups. This is also evidenced in the O1s spectra where this type of group diminishes, with an increased predominance of $\mathrm{O}=\mathrm{C}-\mathrm{N}$, although the makeup of these functional groups differs significantly between the different biomasses at 400 and $600{ }^{\circ} \mathrm{C}$. Similarly, in most samples, an increase in pyridinic $\mathrm{N}$ was observed, although pyrrolic $\mathrm{N}$ remained the dominant form.

\subsection{SEM analysis of morphology}

Figure 7 shows the surface structures of biochars from different feedstocks at two temperature conditions of $400{ }^{\circ} \mathrm{C}$ and $600{ }^{\circ} \mathrm{C}$. Corn waste biochar at $400{ }^{\circ} \mathrm{C}$ and mixed feedstock biochar contain some holes which may be attributed to insufficient carbonization. Many small pores are seen in the biochar due to devolatilization at $600{ }^{\circ} \mathrm{C}$ (Luo et al. 2018). The cracks and pores in the biochars occur due to the release of volatiles and intermediate-size organics (Luo et al. 2018). SEM images obtained for biochar produced from different feedstocks caused substantial changes in the surface morphology and major macroscopic changes were observed for corn biochar.

\subsection{Optimum conditions to biochar as a soil amendment}

It is important to evaluate the results collectively to determine the most suitable vegetable wastes and pyrolysis conditions for an agriculturally efficient biochar, as well as to determine whether combined vegetable waste will significantly diminish the performance. This is important as combined vegetative waste collection and pyrolysis are significantly more simple and economic to implement. The key 
Fig. 7 Surface structure by

SEM analysis a-e at $400{ }^{\circ} \mathrm{C}$ and f-j at $600{ }^{\circ} \mathrm{C}$ for different biochars, respectively. Images were taken at $5000 \times$ with horizontal frame width (HFW) of $82.9 \mu \mathrm{m}$, with exception of (c) (a)

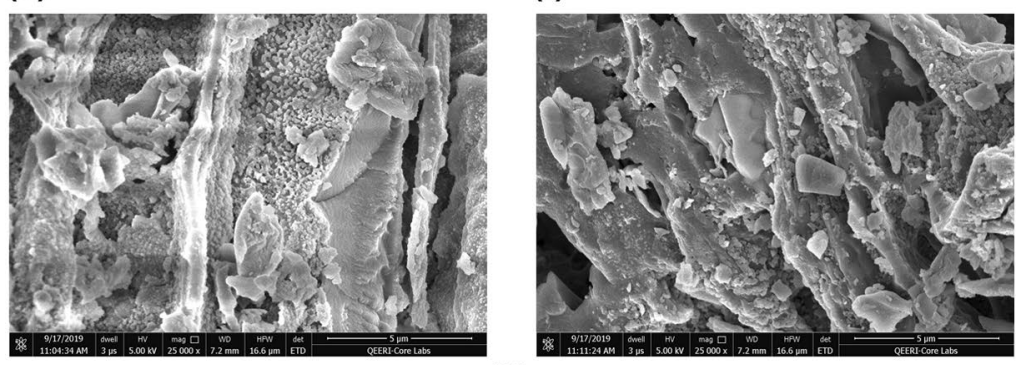

Cauliflower

(b)

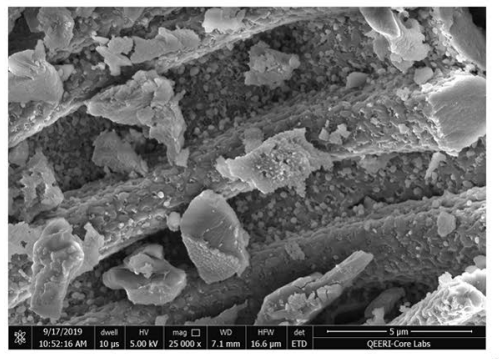

(g)

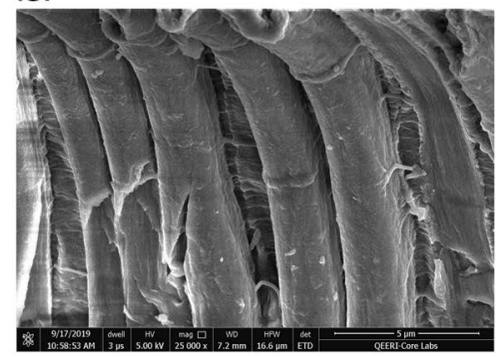

Cabbage

(c)

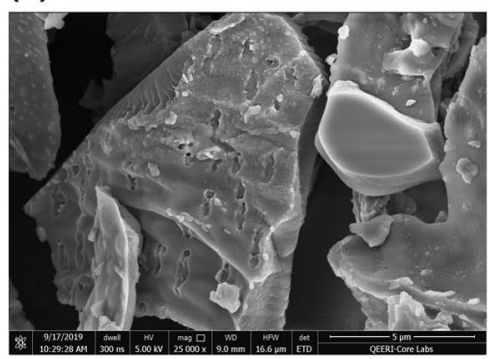

(h)

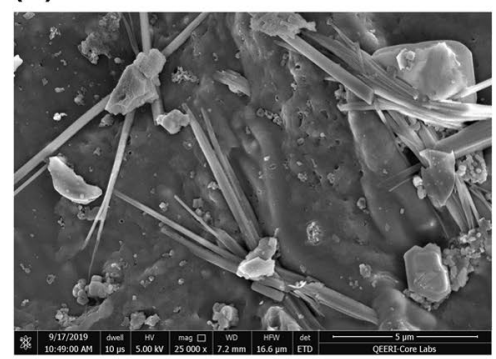

Banana

(d)

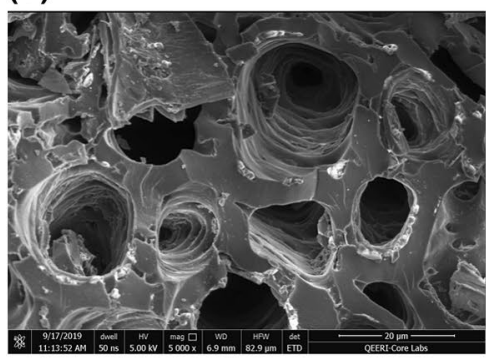

(i)

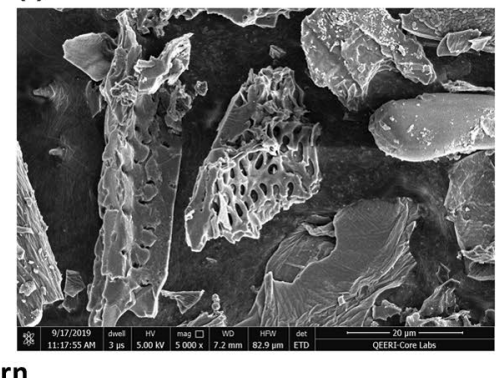

(e)

(j)
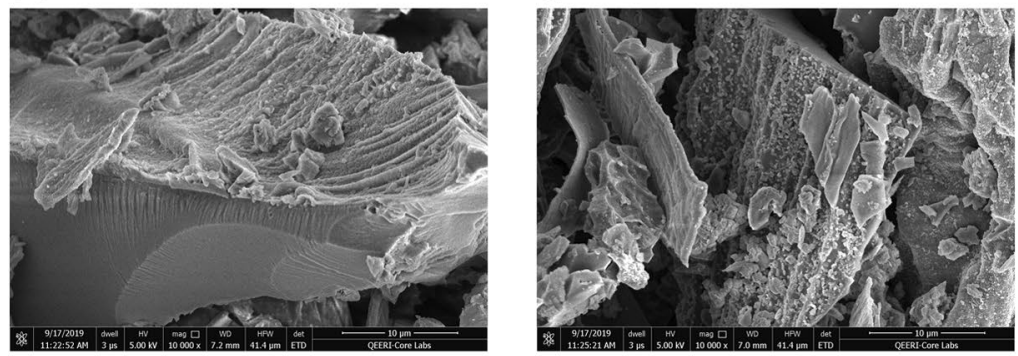

Mix 
characteristics that influence agricultural performance of a biochar are $\mathrm{pH}$ and CEC. Considering these factors, the biochar produced from cauliflower, banana and mixed vegetable waste at temperature of $400{ }^{\circ} \mathrm{C}$ are found to have the most optimum pH (7.62 \pm 0.03$)$ and CEC (37-60 $\left.\mathrm{cmol}_{\mathrm{c}} \mathrm{kg}^{-1}\right)$ to enhance plant growth and water retention capacity (Laghari et al. 2016).

In the literature, studies on biochars produced from waste vegetables are rare. The study by Lee et al. (2017) is the most similar study, where mixed food waste was converted to biochar, including meats, grains, fruits and egg shells in addition to vegetables ( $51 \%$ by mass). The overall composition of the biochar was relatively similar, with an optimum produced at $400{ }^{\circ} \mathrm{C}$, with CEC of $63 \mathrm{cmol}_{\mathrm{c}} \mathrm{kg}^{-1}$. One of the more similar individual materials investigated is orange peel biochar. Sial et al. (2019) produced such material at $350{ }^{\circ} \mathrm{C}$. The biochar had less favorable properties than vegetable waste biochar. Although the ECE was similar at $0.29 \mathrm{mS} \mathrm{cm}^{-1}$, it had much higher $\mathrm{pH}$ of 10.0. The values for individual and mixed vegetable waste biochars are also comparable and competitive with biochars produced from more lignocellulose rich materials (Palansooriya et al. 2019). ECE is generally higher in vegetable waste, which is less desirable, but other properties such as cation exchange capacity and $\mathrm{pH}$ are typically improved with regard to target values for optimum soil improvement.

However, there is a need for further demonstration of food waste-derived biochars in soil test experiments with different soils and plants. Mazac (2016) prepared five different batches of mixed food wastes including vegetables, fruits, leaves and egg shells to produce biochar at a slow pyrolysis temperature condition of $260{ }^{\circ} \mathrm{C}$ for 3 and $6 \mathrm{~h}$ and tested them with tomato plants (Solanum lycopersicum) over 30 days. Similarly, Islam et al. (2019) tested banana peel biochar produced at $400{ }^{\circ} \mathrm{C}$ for $2 \mathrm{~h}$ duration and tested it at 1, 2 and 4\% loading with Ipomoea aquatica. Although both experiments observed improved yield with biochar, neither test showed statistically significant differences.

\section{Conclusion}

The results of this study demonstrate that pyrolysis of various vegetable wastes at temperatures of $300-500{ }^{\circ} \mathrm{C}$ produces biochars with desirable characteristics for agricultural application. Vegetable waste biochar is therefore a suitable approach to reduce food waste environmental burdens and obtain the economic benefits of food waste valorization. This study demonstrated temperature is a dominant factor with low temperatures, suitable for slow pyrolysis, favoring optimum biochar characteristics. Particle size had a minor influence on biochar characteristics, mainly allowing changes to $\mathrm{CEC}$ and $\zeta$-potential. This is important as it means size reduction of raw waste can be optimized for energy consumption and handling prior to pyrolysis. The type of vegetable waste played an important role in biochar properties and it was found that mixed vegetable waste performed as well as the individual vegetable wastes. This confirmation is advantageous, supporting the combined collection and direct conversion of mixed vegetable food waste to biochar. While Keske et al. (2019) have shown biochar application to land for agriculture can have significant economic benefits, both soil testing to confirm the performance of vegetable waste biochar and subsequent economic analysis are necessary in the future.

Acknowledgements The authors would like to thank Qatar National Research Fund for supporting this research under the National Priorities Research Program Grant Number NPRP11S-0117-180328. Any opinions, findings and conclusions or recommendations expressed in this material are those of the author(s) and do not necessarily reflect the views of HBKU or QF. The authors also like to express their thanks to Dr. Yongfeng Tong and Mr. Mohamed I. Helal in Qatar Environment and Energy Research Institute (QEERI), HBKU, for their support toward XPS and SEM analysis.

Funding Open Access funding provided by the Qatar National Library.

\section{Compliance with ethical standards}

Conflict of interest There are no conflicts of interest from the authors.

Open Access This article is licensed under a Creative Commons Attribution 4.0 International License, which permits use, sharing, adaptation, distribution and reproduction in any medium or format, as long as you give appropriate credit to the original author(s) and the source, provide a link to the Creative Commons licence, and indicate if changes were made. The images or other third party material in this article are included in the article's Creative Commons licence, unless indicated otherwise in a credit line to the material. If material is not included in the article's Creative Commons licence and your intended use is not permitted by statutory regulation or exceeds the permitted use, you will need to obtain permission directly from the copyright holder. To view a copy of this licence, visit http://creativecommons.org/licenses/by/4.0/.

\section{References}

Abdelaal AH, McKay G, Mackey HR (2019) Food waste from a university campus in the Middle East: drivers, composition, and resource recovery potential. Waste Manag 98:14-20. https://doi. org/10.1016/j.wasman.2019.08.007

Alotaibi KD, Schoenau JJ (2019) Addition of biochar to a sandy desert soil: effect on crop growth, water retention and selected properties. Agronomy 9:327. https://doi.org/10.3390/agronomy9060327

Al-Rumaihi A, McKay G, Mackey HR, Al-Ansari T (2020) Environmental impact assessment of food waste management using two composting techniques. Sustainability 12:1595. https://doi. org/10.3390/su12041595

ASTM (2007) Standard test method for particle-size analysis of soils D422-63 
ASTM (2010) Standard test method for measuring the exchange complex and cation exchange capacity of inorganic fine-grained soils D7503-10

ASTM (2013) Standard test methods for proximate analysis of coal and coke by macro thermogravimetric analysis D7582-15

Bonanomi G, Ippolito F, Cesarano G et al (2017) Biochar as plant growth promoter: better off alone or mixed with organic amendments? Front Plant Sci 8:1570. https://doi.org/10.3389/ fpls.2017.01570

Bradford KJ, Hsiao TC (1982) Physiological responses to moderate water stress. In: Lange OL, Nobel PS, Osmond CB, Ziegler H (eds) Physiological plant ecology II: water relations and carbon assimilation. Springer, Berlin, Heidelberg, pp 263-324

Brantley KE, Brye KR, Savin MC, Longer DE (2015) Biochar source and application rate effects on soil water retention determined using wetting curves. J Soil Sci 5:1-10. https://doi.org/10.4236/ ojss.2015.51001

Chen Y, Yang H, Wang X et al (2012) Biomass-based pyrolytic polygeneration system on cotton stalk pyrolysis: influence of temperature. Bioresour Technol 107:411-418. https://doi.org/10.1016/j. biortech.2011.10.074

Cheng J, Liu Y, Li Y et al (2018) Preparation of high contents of pyridinic and pyrrolic-nitrogen doped activated-carbon from pyrolysis of purple cabbage for the catalysis of oxygen reduction reaction. Int J Electrochem 13:11203-11214. https://doi.org/10.20964 /2018.11.81

Chun Y, Sheng G, Chiou CT, Xing B (2004) Compositions and sorptive properties of crop residue-derived chars. Environ Sci Technol 38:4649-4655. https://doi.org/10.1021/es035034w

Dai Z, Meng J, Muhammad N et al (2013) The potential feasibility for soil improvement, based on the properties of biochars pyrolyzed from different feedstocks. J Soil Sediment 13:989-1000. https:// doi.org/10.1007/s11368-013-0698-y

Elkhalifa S, Al-Ansari T, Mackey HR, McKay G (2019) Food waste to biochars through pyrolysis: a review. Resour Conserv Recycl 144:310-320. https://doi.org/10.1016/j.resconrec.2019.01.024

FAO (2017) The future of food and agriculture. Accessed 20 Sep 2019

Foong SY, Liew RK, Yang Y et al (2020) Valorization of biomass waste to engineered activated biochar by microwave pyrolysis: progress, challenges, and future directions. Chem Eng J 389:124401. https ://doi.org/10.1016/j.cej.2020.124401

Gao Y, Li T, Fu Q et al (2020) Biochar application for the improvement of water-soil environments and carbon emissions under freeze-thaw conditions: an in-situ field trial. Sci Total Environ 723:138007. https://doi.org/10.1016/j.scitotenv.2020.138007

Gustavsson J, Cederberg C, Sonesson U (2011) Global food losses and food waste: extent, causes and prevention. Food and Agriculture Organization of the United Nations, Rome

Hale SE, Alling V, Martinsen V et al (2013) The sorption and desorption of phosphate-P, ammonium- $\mathrm{N}$ and nitrate- $\mathrm{N}$ in cacao shell and corn cob biochars. Chemosphere 91:1612-1619. https://doi. org/10.1016/j.chemosphere.2012.12.057

Hardy B, Leifeld J, Knicker H et al (2017) Long term change in chemical properties of preindustrial charcoal particles aged in forest and agricultural temperate soil. Org Geochem 107:33-45. https://doi. org/10.1016/j.orggeochem.2017.02.008

Hossain MK, Strezov V, Chan KY et al (2011) Influence of pyrolysis temperature on production and nutrient properties of wastewater sludge biochar. J Environ Manage 92:223-228. https://doi. org/10.1016/j.jenvman.2010.09.008

Huang F, Gao LY, Wu RR et al (2020) Qualitative and quantitative characterization of adsorption mechanisms for $\mathrm{Cd} 2+$ by silicon-rich biochar. Sci Total Environ 731:139163. https://doi. org/10.1016/j.scitotenv.2020.139163
Ippolito JA, Ducey TF, Cantrell KB et al (2016) Designer, acidic biochar influences calcareous soil characteristics. Chemosphere 142:184-191. https://doi.org/10.1016/j.chemosphere.2015.05.092

Islam M, Halder M, Siddique MdAB et al (2019) Banana peel biochar as alternative source of potassium for plant productivity and sustainable agriculture. Int J Recycl Org Waste Agric 8:407-413. https://doi.org/10.1007/s40093-019-00313-8

Jeffery S, Abalos D, Prodana M et al (2017) Biochar boosts tropical but not temperate crop yields. Environ Res Lett 12:053001. https ://doi.org/10.1088/1748-9326/aa67bd

Jien SH, Wang CS (2013) Effects of biochar on soil properties and erosion potential in a highly weathered soil. CATENA 110:225-233. https://doi.org/10.1016/j.catena.2013.06.021

Jindo K, Mizumoto H, Sawada Y et al (2014) Physical and chemical characterization of biochars derived from different agricultural residues. Biogeosciences 11:6613-6621. https://doi.org/10.5194/ bg-11-6613-2014

Junna S, He F, Shao H et al (2016) Effects of biochar application on Suaeda salsa growth and saline soil properties. Environ Earth Sci 75:630. https://doi.org/10.1007/s12665-016-5440-9

Keske C, Godfrey T, Hoag DLK, Abedin J (2019) Economic feasibility of biochar and agriculture coproduction from Canadian black spruce forest. Food Energy Secur. https://doi.org/10.1002/fes3.188

Kizito S, Luo H, Lu J et al (2019) Role of nutrient-enriched biochar as a soil amendment during maize growth: exploring practical alternatives to recycle agricultural residuals and to reduce chemical fertilizer demand. Sustainability 11:1-22

Kookana R, Van Zwieten L, Krull E, Singh B (2011) Biochar application to soil: agronomic and environmental benefits and unintended consequences. Adv Agron 112:103-143. https://doi.org/10.1016/ B978-0-12-385538-1.00003-2

Laghari M, Naidu R, Xiao B et al (2016) Recent developments in biochar as an effective tool for agricultural soil management: a review. J Sci Food Agric 96:4840-4849. https://doi.org/10.1002/ jsfa. 7753

Lam SS, Yek PNY, Ok YS et al (2020) Engineering pyrolysis biochar via single-step microwave steam activation for hazardous landfill leachate treatment. J Hazard Mater 390:121649. https://doi. org/10.1016/j.jhazmat.2019.121649

Lee YE, Jo JH, Kim IT, Yoo YS (2017) Chemical characteristics and $\mathrm{NaCl}$ component behavior of biochar derived from the salty food waste by water flushing. Energies 10:1555. https://doi. org/10.3390/en10101555

Lehmann J, Rillig MC, Thies J et al (2011) Biochar effects on soil biota-a review. Soil Biol Biochem 43:1812-1836. https://doi. org/10.1016/j.soilbio.2011.04.022

Lin D, Pan B, Zhu L, Xing B (2007) Characterization and phenanthrene sorption of tea leaf powders. J Agric Food Chem 55:5718-5724. https://doi.org/10.1021/jf0707031

Liu J, Huang S, Chen K et al (2020) Preparation of biochar from food waste digestate: pyrolysis behavior and product properties. Bioresour Technol. https://doi.org/10.1016/j.biortech.2020.122841

Lou K, Rajapaksha AU, Ok YS, Chang SX (2016) Pyrolysis temperature and steam activation effects on sorption of phosphate on pine sawdust biochars in aqueous solutions. Chem Spec Bioavailab 28:42-50. https://doi.org/10.1080/09542299.2016.1165080

Luo M, Lin H, Li B et al (2018) A novel modification of lignin on corncob-based biochar to enhance removal of cadmium from water. Bioresour Technol 259:312-318. https://doi.org/10.1016/j.biort ech.2018.03.075

Mazac R (2016) Assessing the use of food waste biochar as a biodynamic plant fertilizer. 43. https://digitalcommons.hamline.edu/ dhp/43

Mukherjee A, Zimmerman AR, Harris W (2011) Surface chemistry variations among a series of laboratory-produced 
biochars. Geoderma 163:247-255. https://doi.org/10.1016/j.geode rma.2011.04.021

Mulabagal V, Baah D, Egiebor N, Chen WY (2015) Biochar from Biomass-A strategy for carbon dioxide sequestration, soil amendment, power generation and $\mathrm{CO} 2$ utilization. In: Handbook of Climate Mitigation and Adaptation. pp 1937-1974

Naderi HR, Norouzi P, Ganjali MR (2016) Electrochemical study of a novel high performance supercapacitor based on $\mathrm{MnO}_{2} /$ nitrogendoped graphene nanocomposite. Appl Surf Sci 366:552-560

Palansooriya KN, Wong JTF, Hashimoto Y et al (2019) Response of microbial communities to biochar-amended soils: a critical review. Biochar 1:3-22. https://doi.org/10.1007/s42773-019-00009-2

Patriquin DG, Blaikie H, Patriquin MJ, Yang C (1993) On-farm measurements of $\mathrm{pH}$, electrical conductivity and nitrate in soil extracts for monitoring coupling and decoupling of nutrient cycles. Biol Agric Hortic 9:231-272. https://doi.org/10.1080/01448 765.1993.9754638

Piash MI, Hossain MF, Parveen Z (2016) Physico-chemical properties and nutrient content of some slow pyrolysis biochars produced from different feedstocks. Bangladesh J Sci Res 29:111-122. https ://doi.org/10.3329/bjsr.v29i2.32327

Pituello C, Francioso O, Simonetti G et al (2015) Characterization of chemical-physical, structural and morphological properties of biochars from biowastes produced at different temperatures. J Soils Sediments 15:792-804. https://doi.org/10.1007/s1136 8-014-0964-7

Pokharel P, Ma Z, Chang SX (2020) Correction to: Biochar increases soil microbial biomass with changes in extra- and intracellular enzyme activities: a global meta-analysis. Biochar. https://doi. org/10.1007/s42773-020-00046-2

Rafiq M, Bachmann R, Rafiq MT et al (2016) Influence of pyrolysis temperature on physico-chemical properties of corn stover (Zea mays L.) biochar and feasibility for carbon capture and energy balance. PLoS ONE 11:e0156894. https://doi.org/10.1371/journ al.pone. 0156894

Reza MS, Afroze S, Bakar MSA et al (2020) Biochar characterization of invasive Pennisetum purpureum grass: effect of pyrolysis temperature. Biochar. https://doi.org/10.1007/s42773-020-00048-0

Safian M, Motaghian H, Hosseinpur A (2020) Effects of sugarcane residue biochar and $\mathrm{P}$ fertilizer on $\mathrm{P}$ availability and its fractions in a calcareous clay loam soil. Biochar. https://doi.org/10.1007/ s42773-020-00050-6

Sagar NA, Pareek S, Sharma S et al (2018) Fruit and vegetable waste: bioactive compounds, their extraction, and possible utilization. Compr Rev F Sci F Saf 17:512-531. https://doi. org/10.1111/1541-4337.12330

Sait HH, Hussain A, Salema AA, Ani FN (2012) Pyrolysis and combustion kinetics of date palm biomass using thermogravimetric analysis. Bioresour Technol 118:382-389. https://doi.org/10.1016/j. biortech.2012.04.081

Sakhiya AK, Anand A, Kaushal P (2020) Production, activation, and applications of biochar in recent times. Biochar. https://doi. org/10.1007/s42773-020-00047-1

Saleem J, Shahid UB, Hijab M et al (2019) Production and applications of activated carbons as adsorbents from olive stones. Biomass Convers Biorefin 9:775-802. https://doi.org/10.1007/s1339 9-019-00473-7

Sial TA, Lan Z, Khan MN et al (2019) Evaluation of orange peel waste and its biochar on greenhouse gas emissions and soil biochemical properties within a loess soil. Waste Manag 87:125-134. https:// doi.org/10.1016/j.wasman.2019.01.042

Stenmarck A, Jensen C, Quested T et al (2016) Estimates of European food waste levels. IVL Swedish Environmental Research Institute, Stockholm

Thangalazhy-Gopakumar S, Adhikari S, Ravindran H et al (2010) Physiochemical properties of bio-oil produced at various temperatures from pine wood using an auger reactor. Bioresour Technol 101:8389-8395. https://doi.org/10.1016/j.biortech.2010.05.040

Wang X, Tian Y, Liu H et al (2019) Effects of influent COD/TN ratio on nitrogen removal in integrated constructed wetland-microbial fuel cell systems. Bioresour Technol 271:492-495. https://doi. org/10.1016/j.biortech.2018.09.039

Weil R, Brady N (2017) The nature and properties of soils, (15th edn). Global Edition

Xue S, Zhang X, Ngo HH et al (2019) Food waste based biochars for ammonia nitrogen removal from aqueous solutions. Bioresour Technol 292:121927. https://doi.org/10.1016/j.biort ech.2019.121927

Yuan JH, Xu RK, Zhang H (2011) The forms of alkalis in the biochar produced from crop residues at different temperatures. Bioresour Technol 102:3488-3497. https://doi.org/10.1016/j.biort ech.2010.11.018

Zhao SX, Ta XD, Wang XD (2017) Effect of temperature on the structural and physicochemical properties of biochar with apple tree branches as feedstock material. Energies 10:1293 